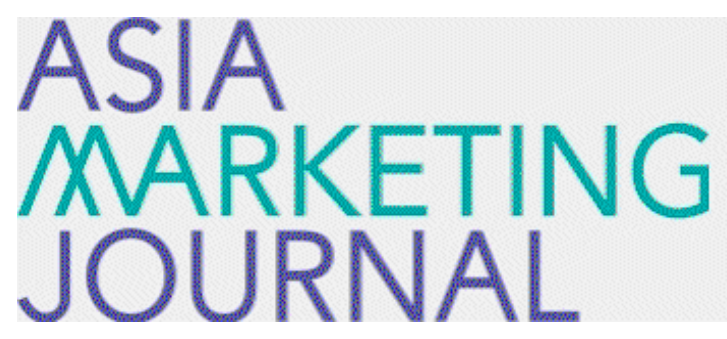

ASIA MARKETING JOURNAL

Volume 11 | Issue 3

Article 1

10-30-2009

\title{
행위의도에 영향을 미치는 확장된 서비스 규범개념과 조절변수에 대한 고찰
}

Sang Hyun Lee

Sang Jun Lee

Follow this and additional works at: https://amj.kma.re.kr/journal

Part of the Marketing Commons

\section{Recommended Citation}

Lee, Sang Hyun and Lee, Sang Jun (2009) "행위의도에 영향을 미치는 확장된 서비스 규범개념과 조절변수 에 대한 고찰," Asia Marketing Journal: Vol. 11 : Iss. 3 , Article 1.

Available at: https://doi.org/10.53728/2765-6500.1391

This Article is brought to you for free and open access by Asia Marketing Journal. It has been accepted for inclusion in Asia Marketing Journal by an authorized editor of Asia Marketing Journal. 


\section{행위의도에 영항을 미치는 \\ 확장된 서비스 규범개념과 조절변수에 대한 고찰*}

\section{A Study of the Extended Service Norm Constructs Influencing Behavioral Intention and a Moderating Variable in Service Purchasing Situation*}

이 상 현(Lee, Sang Hyun)**

이 상 준(Lee, Sang Jun)***

본 연구의 목적은 서비스 이용구매상황에서 기존의 행위예측모델에서 고려되지 않았던 서비스 규 범개념을 정립하고 관련 개념들과의 영향관계를 파악하는 것이다. 아울러 태도와 규범개념이 행위의 도에 미치는 상대적 영향력을 조절하는 변수에 대해 고찰하고자 한다.

연구결과를 살펴보면, 기존의 계획된 행위이론에서 제시했던 소비자 태도, 주관적 규범, 지각된 행 위통제는 이용구매의도에 유의한 영향을 미치는 것으로 나타났다. 본 연구에서 새롭게 확장된 개념으 로 제시한 참여고객 규범 또한 이용구매의도에 영향을 미치는 것으로 나타났다. 하지만 새롭게 확장 된 개념으로 제시한 서비스제공자 규범은 이용구매의도에 영향을 미치지 않는 것으로 나타났다.

아울러 자기 감시성의 조절효과를 $\chi^{2}$ 차이검증을 통해서 비교한 결과, 서비스제공자 규범과 참여 고객 규범이 행위의도에 미치는 영향력에 대한 자기 감시성의 조절효과가 있는 것으로 나타났다.

본 연구는 소비자들이 서비스시스템 내에 있는 다른 참여고객의 반응을 의식한다는 것을 고려하여 주요 고객층들이 서로 잘 어우러질 수 있는 서비스 고객관리에 만전을 기해야 한다는 시사점을 제시 하였다.

핵심개념: 서비스제공자 규범, 참여고객 규범, 행위의도, 자기 감시성

\footnotetext{
* 이 논문은 2006년도 정부재원(교육과학기술부 인문사회연구역량강화사업비)으로 한국학술진흥재단의 지원을 받아 연구 되었음( $\mathrm{KRF}$ - 2006 - 332 - B00149)

** 동국대학교 경영학과 부교수(edlee@dongguk.edu)

*** 동국대학교 경영학과 박사과정(eyorenet@gmail.com)
} 


\section{I. 서 론}

서비스는 제품과 달리 생산과 소비가 동시에 일어나는 비분리성과 경험과정에서 다양한 요 인들(고객, 다른 고객, 서비스제공자들 간의 관 계상황)이 존재함으로 일어나는 이질적인 특성 을 가진다. 무형적인 특질과 더불어 비분리성과 이질성으로 인해 소비자들은 구매의사결정과정 에서 제품을 구매할 때에 비해서 위험을 더 지 각하게 되는 경향이 있다(Zeithaml, Bitner, Gremler 2006). 따라서 제품과는 달리 서비스 구매의사 결정에 있어서도 다소 상이한 점들을 보이게 된다. 예를 들어, 의사결정단계 중 정보탐색단 계에서 제품구매시보다 서비스구매 시에 상대 적으로 인적정보원천에 더 의존한다. 또한 구매 단계에서 서비스구매는 제품구매와 비교해서 경험적인 과정이 더 많이 부각된다. 생산과 소 비를 동시에 경험하므로 구매과정 자체가 더 길고 구매과정에서 영향을 미치는 요인들(서비 스구매과정에 참여하고 있는 다른 고객이나 서 비스제공자 등)이 상대적으로 더 많다. 따라서 서비스 구매행위를 할 때 제품 구매행위에 비 해 무언가 다른 점들을 아울러 고려할 가능성 이 상대적으로 더 많다고 할 수 있다.

Fishbein의 태도이론에 의하면 제품구매 시에 는 고객 자신의 태도가 얼마나 그 제품 브랜드 에 호의적이냐에 따라서 대부분 구매의도가 결 정된다고 하였다. 그 후 Fishbein과 Ajzen (1975, 1980)의 합리적 행위이론(Theory of Reasoned Action: TRA)에서는 태도와 아울러 주관적 규 범이라는 개념을 소개하였다. 이후 Ajzen(1985, $1988,1991)$ 의 계획된 행위이론(Theory of Planned
Behavior: TPB)에서는 합리적 행위이론의 요 인들과 통제된 신념개념까지를 언급하였다. 이 들 행위모델은 지금까지 많은 실증연구를 통해 서 검증되어져 왔다(Farley, Lehman, \& Ryan 1981; Shimp \& Kavas 1984; Sheppard, Hartwick, \& Warshaw 1988; Cooke \& Sheeran 2004; Pavlou \& Fygenson 2006).

하지만 아직도 해결되지 않은 이슈들이 존재 하고 기존의 변수들(태도, 주관적 규범, 통제된 신념)로 설명되지 않는 부분이 있으며, 더 나은 행위예측모델로의 향상을 기대할 수 있는 부분 이 존재한다(Sheeran 2002). 특히 제품구매와 달리 서비스를 이용하거나 구매하는 상황에서 는 비분리성과 이질성으로 인해 특정 서비스상 황에서 대면하게 되는 서비스관련 종사자와 다 른 참여고객들에 대한 인식도 중요한 요인으로 고려되어야 한다(이상현, 유창조, 장문성 2007). 가령, 중년의 고객이 젊은이들이 주로 모이는 홍대부근의 클럽을 이용하려고 한다든지, 젊은 고객이 나이에 어울리지 않게 다소 사치스러운 서비스를 이용하고자 할 때 아무래도 그 서비 스를 이용하고 있는 다른 고객들의 시선이나 그 서비스를 제공하는 사람들의 시선을 의식하 지 않을 수 없을 것이다.

과거의 연구들도 타인에 대한 의식을 고려하 긴 하였지만 대부분 제품구매의도에 초점을 맞 추었고 아울러 개인고객 당사자에게 중요한 영 향을 미치는 사람의 영향력 정도로만 국한시켜 왔다. 따라서 서비스 구매상황에서는 기존의 연 구에서 개인에게 중요한 영향을 미치는 사람들 의 영향력을 나타내는 주관적 규범개념과 아울 러 다른 요인들도 고려하여야 할 필요성이 있 다고 하겠다. 즉, 사회적 압박의 영향변수라는 
측면을 보다 넓게 확장하여 서비스상황에서 개 인 고객에게 의식적으로 의사결정에 영향을 줄 수 있는 개념들을 보다 폭넓게 고려할 필요성 이 있다고 본다.

아울러 합리적 행위이론이나 계획된 행위이론 에서 행위의도와 선행변수들 간의 관계에 영향 을 미치는 몇 가지 조절변수들도 고려되어 왔 다(Cooke \& Sheeran 2004). 하지만 대부분의 연구들은 태도와 행위의도 또는 행동 간의 관 계에 대한 조절변수들에 초점을 맞추어 왔다. 따라서 행위의도에 대한 태도, 주관적 규범, 새 로운 확장규범개념의 상대적인 영향력을 결정 하는 변수에 대한 논의가 필요하다고 본다. 지 금까지의 연구들을 토대로 태도와 행위의도/행 동 간의 관계에서 조절변수들을 크게 구분하면 태도자체의 특성 (태도자신감, 정보의 양, 태도 접근가능성), 개인적 특성(관여도, 자기조절능 력, 인지욕구), 외부적 요소(상황적 제약요인) 등이다. 본 연구에서는 타인의 눈을 의식하는 요인들에 대한 확장을 다루고 있으므로 과거의 여러 조절변수들보다는 새로운 조절변수로서 자기 감시성을 살펴보고자 한다.

본 연구의 목적은 서비스 이용구매상황에서 기존의 행위예측모델에서 고려되지 않았던 새 로운 규범개념을 정립하고 관련 개념들과의 영 향관계를 파악하는 것이다. 아울러 태도와 규범 개념이 행위의도에 미치는 상대적 영향력을 조 절하는 변수에 대해 고찰하는 것이다.

\section{II. 이론적 배경}

\section{1 기존 $\mathrm{TRA}$ 와 $\mathrm{TPB}$ 에 관한 고찰}

태도는 어떤 대상이나 행위에 반응하는 선유 경향이므로 개인은 태도와 일치하는 반응 또는 행위를 할 것으로 예측되어왔다. 이후 많은 사 회심리학자들은 태도가 매번 행동을 예언하지 않으며 태도는 행동에 영향을 미칠 수 있는 여러 요인들 중 하나에 불과하다는 것을 밝혀 왔다(이학식 외 2004). 따라서 태도-행동의 논 쟁에 방법론적 다른 변인들을 함께 고려해야 한다는 주장이 제기되었고, 이는 Fishbein \& Ajzen(1975)의 연구에 의해 신념, 태도, 행위의 도, 행동 간의 관계를 설명한 이후 한 걸음 더 나아간 합리적 행위이론(theory of reasoned action)으로 발전되었다. 그 후 많은 학자들에 의해 검증되어왔고, 이제까지 인간의 행위를 이 해하고 예측하는데 유용하게 사용되었다.

Fishbein \& Ajzen(1975, 1980)의 합리적 행 위이론에 의하면, 사람의 행위는 그 행위를 수 행하려는 의도에 의해 영향을 받게 되고 행위 의도는 그 대상에 대한 태도와 주관적 규범에 의해 영향을 받는다는 것이다. 이는 기존의 특 정대상에 대한 태도가 아니라 특정대상과 관련 한 행위에 대한 태도라는 점에서 행위를 예측 하는데 좀 더 정교하게 다듬어졌다고 할 수 있 다. 합리적 행위이론은 크게 두 가지 관점에서 행동을 설명하였다. 첫 번째는 태도와 주관적 규범이 행위의도에 영향을 미치는 중요한 요인 으로 설명되었다. 두 번째는 특정 행위를 설명 하기 위해서 행위의도가 태도와 주관적 규범이 
특정 행위에 미치는 영향력을 매개하고 있다는 것이다.

이와 같은 합리적 행위이론은 이제까지 제품 선택(Berger \& Mitchell 1989; Fazio, Powell, \& Williams 1989; Petty, Cacioppo, \& Schuman 1983)이나 특정구매상황(Minard \& Cohen 1983; Budd \& Spencer 1984), 쿠폰사용 (Shimp \& Kavas 1984), 인터넷을 통한 전자상거래(김명 소, 한영석 2001; 조대우, 황경연 2001)와 같은 소비행위를 대상으로 검증된 바 있다. 소비행위 와는 전혀 다르게 사회심리학자들의 연구는 대 부분 운동(Sheeran \& Abraham 2003; Bentler and Speckart 1979), 투표(Fazio \& Williams 1986; Pieters \& Verplanken 1995), 헌혈(Burnkrant and Page 1982; Bagozzi 1981), 기부(Cooke \& Sheeran 2004) 등과 같이 개인적인 관심행위나 이타적인 행위를 대상으로 검증되어 왔다.

하지만 합리적 행위이론은 개인의 행위가 자 기통제 하에서 실행될 경우로 한정하고 있으므 로 자기통제에 의해 완전한 통제가 불가능한 경우 특정행위로 이어지지 않는 것에 대한 설 명을 하는데 한계가 있다. 이러한 합리적 행위 이론의 약점을 보완하기 위하여 Ajzen(1985: 1991)은 지각된 행위통제(perceived behavioral control) 라는 개념을 추가하여 계획된 행위이론 을 제시하였다. 계획된 행위이론에서 행위는 행 위의도와 지각된 행위통제에 의해 결정되고, 행 위의도는 행위에 대한 태도, 주관적 규범, 지각 된 행위통제 등에 의해서 결정된다는 것이다. 지각된 행위통제는 개인이 그 행위를 수행하는 것에 대해 쉽게 생각하는 정도를 말한다. 그동 안 많은 논쟁이 있었지만 대체적으로 TPB 모 델과 TRA 모델의 비교연구에서 TPB가 행위
와 행위의도를 설명하는 정도가 더 우세한 것 으로 나타나고 있다(Madden, Ellen, and Ajzen 1992; Schlegel, et al. 1992). 이처럼 TPB가 예 측력이 우세하며 TPB 모델에 설명변수들(예: 과거 경험)을 추가했을 때 설명력이 그리 높아 지지 않는다는 것을 검증한 바 있다(Ajzen 1991). 두 모델간의 간략한 비교는 다음의〈표 1〉과 같다.

$\mathrm{H} 1$ : 서비스이용에 대한 태도가 호의적일수 록 서비스 이용/구매의도는 높아질 것 이다.

$\mathrm{H} 2$ : 서비스이용에 대한 주관적 규범의 정도 가 높을수록 서비스 이용/구매의도는 높아질 것이다.

H3: 서비스이용에 대한 지각된 행위통제의 정도가 높을수록 서비스이용/구매의도 는 높아질 것이다.

\section{2 규범개념의 확장}

기존의 합리적 행위이론에서는 태도 이외에 사 회 환경 안에서 다른 사람들에 대한 규범적 영 향력을 반영하였다. 주관적 규범은 어떤 행위여 부를 결정하는데 있어 개인에게 중요한 타인들 이 어떤 의견을 가질 것인가를 생각하고 이를 따르는 경향을 나타내는 것이다(Ajzen 1991). 이러한 주관적 규범의 개념은 사회적 영향 또 는 사회적 압력으로 대변될 수 있다(Igbaria, Zinatelli, and Cragg 1997). 합리적 행위란 소 비자들이 주어진 상황에서 있을 수 있는 여러 가지 행동의 결과들을 의식적으로 검토하고 가 장 좋은 결과를 낳는 것을 선택하는 것을 의미 
〈표 1〉TRA와 TPB의 상호비교

\begin{tabular}{|c|c|c|}
\hline & $\begin{array}{c}\text { TRA: theory of reasoned action } \\
\text { (합리적 행위이론) }\end{array}$ & $\begin{array}{l}\text { TPB: theory of planned action } \\
\text { (계획된 행위이론) }\end{array}$ \\
\hline 이론 & $\begin{array}{l}\text { 행위태도 모형에 개인의 주관적 규범과 행 } \\
\text { 위의도를 결합한 태도모형 }\end{array}$ & $\begin{array}{l}\text { 합리적 행위모형에 행동 통제력인 지각된 행위통 } \\
\text { 제를 결합한 태도모형 }\end{array}$ \\
\hline 독립 개념 & 행위에 대한 태도, 주관적 규범 & 행위에 대한 태도, 주관적 규범, 지각된 행위통제 \\
\hline 종속 개념 & 행위의도, 행위 & 행위의도, 행위 \\
\hline 모형 & $\begin{array}{l}\mathrm{B} \approx \mathrm{BI}=\mathrm{w}_{1} \cdot \mathrm{AB}+\mathrm{w}_{2} \cdot \mathrm{SN} \\
\mathrm{B}: \text { 행위 } \\
\mathrm{BI} \text { 행위의도 } \\
\mathrm{AB} \text { : 행위에 대한 태도 } \\
\mathrm{SN} \text { : 주관적 규범 } \\
\mathrm{w}_{1}, \mathrm{w}_{2} \text { : 상대적 중요도에 대한 가중치 }\end{array}$ & $\begin{array}{l}\mathrm{B} \approx \mathrm{BI}=\mathrm{w}_{1} \cdot \mathrm{AB}+\mathrm{w}_{2} \cdot \mathrm{SN}+\mathrm{w}_{3} \cdot \mathrm{PBC} \\
\mathrm{B}: \text { 행위 } \\
\mathrm{BI} \text { 행위의도 } \\
\mathrm{AB} \text { : 행위에 대한 태도 } \\
\mathrm{SN} \text { : 주관적 규범 } \\
\mathrm{PBC} \text { : 지각된 행위통제 } \\
\mathrm{W}_{1}, \mathrm{w}_{2}, \mathrm{w}_{3} \text { : 상대적 중요도에 대한 가중치 }\end{array}$ \\
\hline
\end{tabular}

한다(Ajzen 1991).

그 중요한 역할을 하고 있는 개념이 주관적 규범이다. 이것은 곧 개인이 활용할 수 있는 정 보를 합리적이고 체계적으로 사용하며, 대부분 개인의 사회적 행위가 의지에 의해 통제될 수 있다는 가정에 근거하고 있다. 하지만 과연 서 비스이용/구매행태와 관련해서 개인에게 중요 한 타인(예: 부모님, 친구, 애인 등)만이 의식 할 수 있는 대상이고 그들의 생각만을 반영하 는 것이 사회적 행위에 대한 충분한 설명으로 보기에는 다소 미흡하다.

서비스구매행위에 있어서 소비자의 지각된 위 험은 제품구매행위에 있어서의 위험보다 더 크 다. 그 이유는 서비스가 쉽게 보여지기 힘든 무 형적인 특질을 가지고 있고, 종업원이나 고객, 그리고 상황에 따라 이질적인 모습을 보일 수 있으며, 생산과 소비가 거의 동시에 일어나기 때문이다(Parasuraman, Zeithaml, and Berry 1985; Zeithaml, Bitner, Gremler 2006). 특히
서비스제공자와 소비자 그리고 그 서비스 상황 에 있는 참여고객 모두의 상호작용에 의해서 발 생하는 이질적인 특성은 서비스 구매행위 연구 에 있어 매우 중요하게 생각해야 할 요소이다.

서비스행태와 관련한 연구에서 중요한 부분을 차지하는 연구 분야 중 하나가 만족/불만족과 서비스 재구매의 영향관계라고 할 수 있다. 이 와 관련한 과거의 서비스연구에 의하면 소비자 와 직접적인 접촉관계에 있는 서비스제공자가 어떤 고객의 행위여부를 결정짓는데 매우 중요 한 역할을 한다는 것을 알 수 있다(Czepiel 1990; Gittell 2002; Chebat and Kollias 2000). 이와 더불어 서비스 시스템 안에서 함께 서비스를 제공받는 다른 참여고객의 역할 또한 중요하다 고 주장한다(Bettencourt 1997; Grove \& Fisk 1997). 그렇다면 서비스이용/구매행위를 생각할 때, 기존의 합리적 행위이론에서 주장하는 주관 적 규범뿐만 아니라 서비스제공자와 그 서비스 에 참여하고 있는 다른 고객들에 대한 개인의 
의식을 반영하는 것이 좀 더 사회적 영향 또는 사회적 압력으로 대변되는 규범의 개념을 충분 히 잘 설명할 수 있을 것이다.

아직까지 규범의 확장과 관련한 논의는 거의 없는 실정이다. 하지만 몇몇 연구에서 그러한 생각들이 잉태되고 있음을 알 수 있다. Ajzen (1991)은 주관적 규범 이외에 개인적 또는 도 덕적 규범(어떤 특정 행동을 하거나 하지 않거 나 하는 등의 도덕적 책임으로 생각하는 개인 적 느낌)이 행위의도나 실제 행동을 설명하거 나 예측하는데 도움을 줄 수 있다고 언급하였 다. 이러한 개인적 규범은 서비스이용 상황에 있어서 서비스제공자나 다른 고객을 인식함으 로서 나올 수 있는 개념이라고 볼 수도 있다.

유창조(2004)의 연구는 규범의 확장에 관한 실마리를 제공하고 있다. 그는 브랜드의 범위를 브랜드 자체뿐만 아니라 브랜드 관리자 및 매 장 주인 등으로 확대하여 해석하게 되면 '소비 자 구매행동에 대한 브랜드의 태도'가 구매행동 에 미치는 영향은 보다 크게 나타날 수 있다고 하였다. 예를 들면, 서비스가 제공되는 상황에 서 소비자는 매장 직원의 반응을 더 의식할 수 있다는 것이다. 비록 그의 연구는 서비스제공자 에 대한 의식만을 구매행위에 영향을 미칠 수 있는 요소로 제안하고 있지만 서비스상황에서 좀 더 확장해 보면 앞에서 이야기한대로 다른 참여고객 또한 중요한 영향요소로 볼 수 있는 것이다. 이상현, 유창조, 장문성(2007)의 연구에 서는 실제 서비스참여고객 반응개념을 소개하 고, 이를 합리적 행위이론의 다른 변인들과 함 께 분석하였다. 서비스참여고객 반응개념은 서 비스가 이루어지는 현장에서 관계자를 의식하 는 것으로 종업원이나 다른 고객을 따로 구분
하지 않고 모두 한꺼번에 고려하였다.

이러한 관점에서 본 연구는 서비스상황에서 서비스제공자와 참여고객에 대한 인식이 어떤 서비스이용의도에 각각 중요한 영향력을 미칠 수 있다고 가정하였다. 이를 바탕으로 '서비스 제공자 규범’과 ‘참여고객 규범’이라는 새로운 개념을 소개하고자 한다. 이 개념은 Fishbein \& Ajzen(1975)의 합리적 행위이론에서 제시하는 ‘주관적 규범'이라는 변수에서 파생, 확장된 개 념으로 볼 수 있다. 주관적 규범은 소비자가 자 신의 구매행동을 할 때 자신과 관계되는 주변 (자신이 중요하다고 인식하는 가족이나 친구 등)을 의식하는 것이라면 '서비스제공자 규범' 과 '참여고객 규범’은 소비자가 자신과 관계는 없으나 특정 서비스를 소비하는 상황에서 접하 게 되는 사람들(종업원이나 서비스장소에서의 다른 고객들)을 의식하는 것이라고 볼 수 있다.

이와 같이 인간은 특정상황에서 주변에 있는 사람들을 의식하게 되고, 이러한 의식이 인간의 행동에 영향을 준다는 것은 이미 사회심리학 분야에서 많이 분석되어 왔다. 마찬가지로 소비 자는 자신이 특정 서비스를 소비하는 상황에서 접하게 되는 여러 계층의 사람을 의식하게 되 고, 이에 의하여 행동이 영향을 받을 것이라고 본 연구는 제안하는 것이다. 이러한 규범개념은 실제로 서비스제공자나 다른 참여고객들이 특 정 개인소비자의 구매행위를 어떻게 생각하는 가와 관계없이 소비자의 서비스이용/구매행동 에 영향을 줄 수 있다. 왜냐하면 이 개념들은 특정 개인소비자가 서비스제공자와 참여고객의 반응을 스스로 추론하여 의식하는 것이기 때문 이다. 
$\mathrm{H} 4$ : 서비스이용에 대한 서비스제공자 규범 의 정도가 높을수록 서비스이용/구매의 도는 높아질 것이다.

$\mathrm{H} 5$ : 서비스이용에 대한 참여고객 규범의 정 도가 높을수록 서비스이용/구매의도는 높아질 것이다.

\section{3 행위의도에 미치는 상대적 영향력과 조절변수의 역할}

기존의 행위의도 모델에서는 태도요인과 주관 적 규범의 상대적인 영향력을 설명하면서 일반 적으로 규범요인보다는 태도요인이 더 큰 영향 을 미치는 것으로 보고 태도변화 전략을 강조 해 왔다(Ajzen \& Fishbein 1980; Lutz 1991). 하지만 몇몇 연구는 상대적인 중요성에 있어서 대조적인 입장을 나타내고 있다. 즉, 태도보다 는 규범이 더 중요한 것으로 나타나고 있는 것 이다(Skinner \& Cattarello 1989; Bearden \& Woodside 1978; Warshaw 1980; Budd 1986). 특히 Budd(1986)의 연구에서는 흡연행위를 예 측하는데 있어서 흡연자와 비흡연자의 태도요 인과 규범요인이 다른 영향력을 가지는 것으로 나타났다. 흡연행위를 예측하는데 있어서 비흡 연자의 경우에는 규범적 요인이 흡연자의 경우 에는 태도요인이 더 높은 영향력을 가지는 것 으로 나타났다. 또한 Warshaw (1980)는 껌, 잡 지(time지), 음료수, 10 불이상의 외식을 구매하 는 행위에 대한 연구를 하였는데, 10 불 이상의 외식구매에 대한 경우에만 주관적 규범의 상대 적인 가중치가 높게 나타났다. 아울러 Skinner \& Cattarell(1989)의 연구에서는 행위가 일어나 는 장소와 행위몰입에 의해서 태도와 규범의
상대적인 영향력의 차이가 있다고 주장하였다.

이러한 것을 종합해 볼 때, 상황에 따라서 태 도나 규범의 영향력이 달라지거나 적어도 변동 이 있을 수 있다는 것을 유추할 수 있다. 관여 도를 포함한 여러 가지 조절변수들을 생각할 수 있겠지만, 본 연구에서는 규범개념에 집중하 고 있기 때문에 행위의도에 미치는 상대적 영 향력의 중요한 조절변수로 자기 감시성 (selfmonitoring)을 고려하고자 한다.

자기 감시성은 Snyder(1974)의 연구 이후 사 회심리학과 소비자 행동분야에서 많은 관심을 받기 시작했다. 특히 자기 감시성은 사람과 사 람간의 대인관계에 있어서 중요한 영향력을 가 지고 있다고 할 수 있다(Slama \& Celuch 1995). 자기 감시성이란 한 개인이 사회적 단서에 따 라 자신의 표현행위를 관찰하고 통제하는 정도 라고 정의한다(Gould 1993, Snyder 1979). 일반 적으로 자기 감시성이 높은 개인집단과 낮은 개인집단으로 나누어 생각해 볼 수 있다. 개인 의 행위는 외부적 상황에 영향을 받는 정도에 따라 달라질 수 있는데, 자기 감시성이 높은 집 단은 사회적 단서에 민감하여 사회적으로 적절 한 행위를 보이는 사회적 단서에 민감하고 이 러한 단서를 이용하여 자신의 행위를 수정하려 고 하는 경향이 있다. 반면에 자기 감시성이 낮 은 집단은 사회적 단서에 덜 민감하여 여러 다 른 상황들에서도 자신의 행위를 동일하게 유지 하는 경향이 있다(Aron O'Cass 2000). Snyder (1979)는 자기 감시성이 높을수록 사회적 규범 에 민감하여 상황적 정보에 의해 특정 행위를 하게 된다고 하였다. 반면, 자기 감시성이 낮을 수록 자신의 내부정보에 근거하여 특정 행위를 하게 된다고 하였다. 
자기 감시성에 대한 조절적 역할을 규명하려 했던 과거 연구들을 살펴보면 태도와 행위의도 간의 관계에서 자기 감시성의 조절적 역할을 규명했지만 몇몇 연구들은 조절적 역할을 규명 하는데 실패하였다(Ajzen et al. 1980, Snyder \& Kendzierski 1982, 이학식과 김영 1998). 이 처럼 자기 감시성의 조절적 역할이 다소 미미 한 것으로 나타나고 있다. 하지만 서비스구매 이용상황은 기존의 제품구매상황과는 매우 다 르다. 사회적 규범에 민감하다면 서비스규범이 태도보다 상대적으로 더 강한 영향력을 미칠 수 있다고 볼 수 있기 때문이다. 따라서 자기 감시성의 역할이 제품구매 상황보다는 더 클 수도 있을 것이다. 본 연구에서는 계획된 행위 이론을 확장시키는 과정에서 특히 서비스구매 행위의 상황에서 탐색적으로나마 자기 감시성 의 조절적 역할에 대해 살펴보고자 한다.

$\mathrm{H} 6$ : 자기 감시성 수준이 높을수록 규범요소 (주관적 규범, 서비스제공자 규범, 참여 고객 규범)가 행위의도에 미치는 영향 은 더 크게 나타날 것이다.

\section{III. 연구모형}

본 연구에서는 위에서 설명한 이론적 배경과 가설을 바탕으로 확장된 규범개념의 영향력과 개인성향의 조절적 역할을 알아보고자 다음의 〈그림 1〉과 같은 연구 모형을 제시하였다. 연구 모형은 기존의 $\mathrm{TPB}$ 모델에서 제시한 세 가지 개념(태도, 주관적 규범, 지각된 행위통제)과
본 연구에서 제안하는 확장된 새로운 두 가지 규범(서비스제공자 규범, 참여고객 규범)이 행 위의도에 미치는 영향력 관계를 나타내고 있다. 〈그림 1)에서 보는 바와 같이 기존의 TPB 모 델(Ajzen 1991, 2002)에서 제시한 개념들을 서 비스상황에 적용하여 서비스이용행위에 대한 태도, 서비스이용행위에 대한 주관적 규범, 지 각된 행위통제 모두 행위의도에 영향을 미치는 영향변수로 가정한다.

확장된 규범개념인 서비스제공자 규범은 주관 적 규범과 달리 소비자가 자신과 관계는 없으 나 특정 서비스를 소비하는 상황에서 접하게 되는 종업원을 의식하는 것이다. 서비스이용 의 사결정상황에서 이러한 서비스제공자 규범은 행위의도에 영향을 미칠 것으로 가정한다. 마찬 가지로 참여고객 규범은 자신과 관계는 없으나 특정 서비스를 소비하는 상황에서 관계될 수 있는 다른 참여고객을 의식하는 것으로 볼 수 있다. 이는 곧 참여고객 규범으로 행위의도에 영향을 미칠 것으로 가정한다.

또 다른 영향변수들로 본 연구에서는 자기 감시 성을 제시하고 있는데 이는 직접적인 영향력보다 는 행위의도에 영향을 미치는 태도와 규범의 상 대적인 영향력을 조절하는 변수로 제시되고 있다.

본 연구에서는 행위의도에 영향을 미치는 두 가지 새로운 규범과 기존 변수들이 행위의도에 미치는 영향관계를 실증하는데 그 초점이 있다. 행위의도가 실제 행위를 예측하는데 충분한 영 향력을 발휘하는 가에 대해서는 논쟁의 여지가 있다. 하지만 대체로 행위의도가 잘 형성된 경 우에는 실제행위를 충분히 설명할 수 있는 것 으로 볼 수 있으므로 행위의도와 실제 행위와 의 관계에 대한 직접적인 실증분석은 생략하기 
〈그림 1〉연구모형

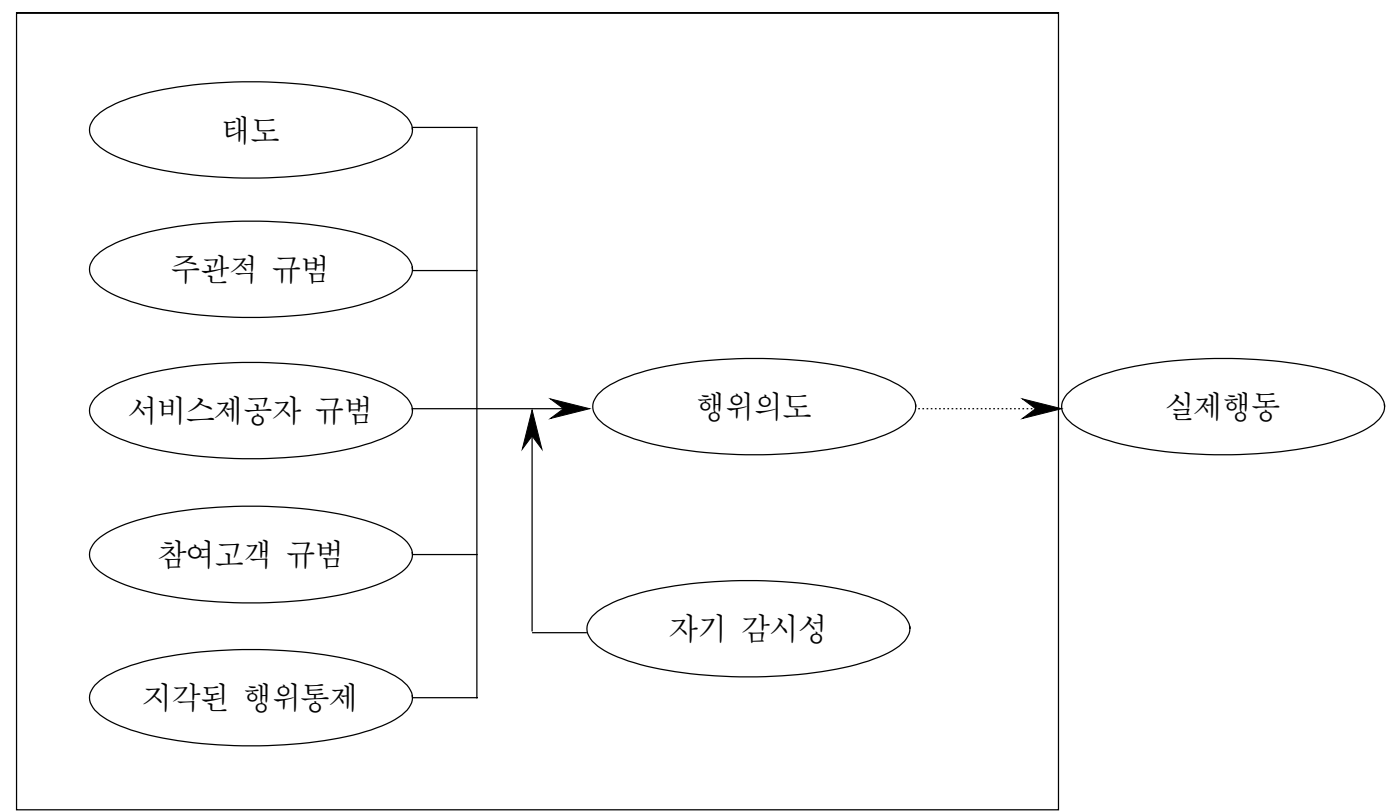

로 한다. 따라서 실제 본 연구의 모형은 〈그림 $1>$ 에서 네모 안에 있는 변수들의 연관관계를 검증하는데 있다고 할 수 있다.

\section{IV. 연구방법}

\section{1 서비스 종류의 선정 및 표본}

본 연구를 실행함에 있어서 가장 먼저 고려되 어야 할 점은 서비스 종류와 상황에 대한 선정 이다. 왜냐하면 서비스의 범위가 매우 광범위하 고 각 서비스의 유형에 따라 매우 다른 영향관 계와 해석이 있을 수 있기 때문이다. 본 연구에 서는 태도나 주관적 규범 이외에도 규범의 확 장개념에 대한 영향력이 잘 드러날 수 있는 서
비스상황을 고려하였다. 일차적으로 서울시내 한 대학의 학부생들과 교직원을 대상으로 다양 한 서비스 이용 상황의 시나리오에 대해 직접 면접 설문조사를 실시하였다.

본 연구에서는 서비스의 이용가능 상황을 설 정하여 설문에 응답하도록 하였다. 직접면접조 사를 통하여 얻어진 정보를 토대로 하여 다양 한 서비스이용 상황(골프장 이용, 콜라텍 이용, 7080 콘서트 이용, 이/미용실 서비스, 홍대클럽 이용, 세신(때밀이) 서비스 등)을 고려한 끝에 최종적으로 두 가지 다른 서비스상황을 선정하 였다.

첫 번째 서비스는 특정계층을 겨냥한 문화이 용 서비스로서 다른 참여고객과의 교감이 중요 하다고 생각되는 홍대클럽이용 서비스상황을 선정하였다. 특히 젊은 층에서는 비교적 남의 눈을 의식하지 않고 홍대클럽을 비교적 자유롭 
게 이용하지만, 중년층들은 사회적 규범 그리고 그 서비스 이용 상황에서 발생하는 다른 참여 고객이나 종업원과의 상호관계를 의식할 수 있 는 서비스 이용/구매 상황이라 생각하였다.

두 번째 서비스는 대중목욕탕을 이용할 때 선 택할 수 있는 세신(때밀이) 서비스이용 상황을 선정하였다. 세신 서비스는 홍대클럽이용 서비 스와는 반대로 비교적 젊은 층에서 사회적 규 범이나 다른 참여고객 또는 종업원을 의식할 수 있는 서비스 이용/구매상황이라 생각하였다. 최종적으로 표준화된 설문지를 가지고, 자료조 사원들을 고용하여 서울 시내 인구 밀집 지역 에서 대학생과 일반 성인을 대상으로 각각 다 른 서비스이용 상황설문에 대해 250명씩 총 500 명에게 직접면접조사를 통하여 자료를 수집 하였다. 불성실하게 응답한 것으로 판단되는 설 문지 16 부를 제외한 총 484 부의 설문지를 최종 분석에 사용하였다.

\section{2 변수의 측정}

\subsection{1 서비스이용/구매에 대한 태도}

행위에 대한 태도는 어떤 대상과 관련된 행위 에 대해 일관성 있게 호의적 또는 비호의적으 로 반응하려는 학습된 경향을 의미한다. 소비자 의 서비스이용/구매 태도에 대한 측정은 Ajzen (2002)의 연구와 이학식 외(2004)의 연구에서 사용된 소비자 태도척도를 바탕으로 하여 본 연구의 각 시나리오 상황에 맞도록 수정하여 설문한다. 소비자의 서비스이용/구매 태도항목 을 다섯 개의 7점 의미차별화 척도를 사용하여 측정한다. 홍대클럽 서비스이용에 대한 태도를
측정한 항목은 다음과 같다: 내가 홍대클럽을 이용하는 것은 나쁘다/좋다, 어리석다/현명하 다, 즐겁지 않다/즐겁다, 바람직하지 않다/바람 직하다, 해롭다/유익하다(전혀 그렇지 않다-매 우 그렇다).

\subsection{2 서비스이용/구매에 대한 주관적 규범}

서비스 이용/구매에 대한 주관적 규범은 지각 된 준거집단의 의견을 나타내는 것으로 내가 중요하게 여기는 대부분의 사람들이 내가 특정 행위를 수행해야 한다고 생각하거나 또는 수행 하지 않아야 한다고 생각하는 것에 대한 개인의 지각을 의미한다. 주관적 규범은 Ajzen(2002)의 연구에서 사용된 척도를 바탕으로 하여 본 연 구의 각 시나리오 상황에 맞도록 수정하여 설 문한다. 홍대클럽 이용과 관련한 설문내용은 다 음과 같다: 내가 중요하게 생각하는 사람들은 내가 홍대클럽을 이용해야 한다고 생각한다, 내 가 소중하게 생각하는 사람들은 내가 홍대클럽 을 이용해야 한다고 생각한다, 나의 주변 사람 들은 내가 홍대클럽을 이용해야 한다고 생각한 다(전혀 그렇지 않다-매우 그렇다).

\subsection{3 서비스이용/구매에 대한 서비스제공자 규범}

서비스이용/구매에 대한 서비스제공자 규범은 지각된 홍대클럽 종사자의 의견을 나타내는 것 으로 내가 만나게 되는 홍대클럽의 종업원들이 내가 홍대클럽 서비스를 이용해야 한다고 생각 하거나 또는 이용하지 않아야 한다고 생각하는 것에 대한 개인의 지각을 의미한다. 서비스제공 
자 규범은 Ajzen(2002)의 연구에서 사용된 주 관적 규범측정 항목을 서비스 상황에 맞게 수 정하여 측정하였다. 다음은 세부측정 항목이다: 홍대클럽 종사자는 내가 홍대클럽을 이용해야 한다고 생각한다, 홍대클럽 종사자는 내게 홍대 클럽 이용을 권유 할 것이다, 홍대클럽 종사자 는 내가 홍대클럽을 이용할 때 적극적으로 도움 을 줄 것이다(전혀 그렇지 않다-매우 그렇다).

\subsection{4 서비스이용/구매에 대한 참여고객 규범}

서비스이용/구매에 대한 참여고객규범은 위의 서비스제공자 규범과 마찬가지로 지각된 홍대 클럽을 이용하는 다른 참여고객의 의견을 나타 내는 것으로 내가 만나게 되는 홍대클럽의 다 른 참여고객들이 내가 홍대클럽 서비스를 이용 해야 한다고 생각하거나 또는 이용하지 않아야 한다고 생각하는 것에 대한 개인의 지각을 의 미한다. 참여고객 규범은 Ajzen (2002)의 연구 에서 사용된 주관적 규범의 측정 항목을 서비 스 상황의 다른 참여고객을 가정하여 수정하였 다. 세부측정 항목은 다음과 같다: 홍대클럽을 이용하는 다른 고객들은 내가 홍대클럽을 이용 해야한다고 생각한다, 홍대클럽을 이용하는 다 른 고객들은 내게 홍대클럽이용을 권유할 것이 다, 홍대클럽을 이용하는 다른 고객은 나의 홍 대클럽이용에 적극적으로 도움을 줄 것이다(전 혀 그렇지 않다-매우 그렇다).

\section{2 .5 지각된 행위통제}

지각된 행위통제는 개인이 그 행위를 수행하 는 것에 대한 자신감의 정도를 나타낸다. Ajzen
(2002)에서 제시한 측정항목을 수정하여 다음 과 같은 측정항목을 만들었다: 나는 홍대클럽 서비스를 이용할 만한 능력이 있다, 나는 홍대 클럽에서 자신 있게 즐길 수 있다, 나는 홍대클 럽을 이용할 만한 능력이 있다, 홍대클럽을 이 용할지 안할지는 전적으로 나에게 달려있다(매 우 동의하지 않는다-매우 동의한다).

\section{2 .6 이용/구매 의도}

서비스 이용/구매의도는 Ajzen(2002)의 연구 에서 사용된 측정항목을 본 연구 상황에 맞게 수정하여 다음의 세 가지 항목을 가지고 7점 척도로 측정하였다: 나는 향후 홍대클럽을 이 용할 의도가 있다, 나는 앞으로 홍대클럽을 이 용할 계획이 있다, 나는 가까운 미래에 홍대클 럽을 이용할 것이다(전혀 그렇지 않다-매우 그 렇다).

\subsection{7 자기 감시성}

자기 감시성은 Snyder \& Gangestad(1986)와 이학식과 김영(1998)의 연구에서 사용된 측정 항목을 본 연구 상황에 맞게 수정하여 총 7 가 지의 항목을 가지고 7점 척도로 측정하였다: 나는 단체 회식이나 모임에서 다른 사람들이 좋아할 만한 말을 하거나 그러한 행동을 하려 고 시도하는 편이다, 나는 사람들 속에서 주목 을 받는 경우가 흔히 있다, 나는 상황에 따라서 가끔 평소의 나와는 다른 사람처럼 행동하곤 한다, 나는 다른 사람들이 나를 좋아하도록 만 드는데 능숙하다, 나는 다른 사람을 기쁘게 하 거나 그들의 호의를 얻기 위해서 내 의견을 쉽 
사리 바꾼다, 나는 흥을 돋우는 사람으로 여겨 져 왔다, 나는 다른 사람들과 잘 어울리며, 내 가 그들과의 사회적 관계에서 해야 하는 만큼 충 분히 잘 한다(전혀 그렇지 않다 - 매우 그렇다).

\section{$\mathrm{V}$. 실증분석 및 결과}

본 연구에서는 SPSS 16.0을 이용하여 탐색적 요인분석을 하였고, $\mathrm{AMOS} 16.0$ 으로 확인적 요 인분석, 측정 동일성 검증, 구조방정식 모형분 석, 다중집단 분석을 하였다. 구조방정식 모형 분석 중 자기 감시성의 조절효과 분석을 위해 자기 감시성을 측정한 7 개 문항을 평균 낸 중 위수(median)인 4.333을 기준으로 낮은 집단 (자기 감시성<4.333)과 높은 집단(자기 감시 성>4.333)으로 나눈 후 다중집단 분석을 실시하 였다. 다중집단 분석을 통해 조절효과 판단을 하는 절차는 각 집단의 해당 경로를 제약을 하 지 않은 자유모형과 그 경로를 두 집단에 동일 하게 제약한 모형을 각각 분석한 후 두 모형 간 에 $\chi^{2}$ 차이검증을 실시하여 유의성 여부를 판 단하였다.

\section{1 신뢰성 및 타당성 검증}

본 연구에서는 측정변수들의 각 항목을 모두 선택하여 각 변수를 측정하는 항목들이 잘 분 리되는지 알아보고자 탐색적 요인분석을 실시 하였고, 내적일관성을 의미하는 Cronbach's a 값을 가지고 신뢰성을 검증하였다. 분석 결과 추출된 요인들을 구성하고 있는 항목들의 적재값
은 모두 0.7 이상으로 나타났다. 또한 Cronbach's $\mathrm{a}$ 값은 최저 0.851 에서부터 최고 0.945 를 나타 내고 있어 구성개념간의 내적일관성이 높은 것 으로 나타났다. 구성개념에 대한 탐색적 요인분 석과 신뢰도분석은 〈표 2〉에 나타나 있다.

또한 구성개념에 대한 탐색적 요인분석으로 추출된 측정항목에 대해 확인적 요인분석을 실 시하였다. 분석 결과, 전반적인 적합도는 $\chi^{2}$ $(155)=468.239(\mathrm{p}=0.000), \mathrm{GFI}=0.910, \mathrm{AGFI}=$ 0.879, $\mathrm{NFI}=0.940, \quad \mathrm{NNFI}=0.949, \quad \mathrm{CFI}=0.959$, $\mathrm{RMSEA}=0.065$ 로 나타났다. 이를 살펴보면 GFI $(\geq 0.90), \quad \operatorname{NFI}(\geq 0.90), \quad \mathrm{NNFI}(\geq 0.90), \quad \mathrm{CFI}(\geq$ $0.90), \operatorname{RMSEA}(\leq 0.08)$ 는 모형적합도의 기준 치를 만족시키고 있는 것으로 나타났다. 다만 $\mathrm{AGFI}=0.879$ 로서 0.9 의 권고수준 $(\mathrm{Gefen}$, et al., 2000)에는 약간 못 미치지만, 양호하다고 판단 되는 0.8의 권고수준(Chau, 1996; Taylor and Todd, 1995)은 초과하는 적합도 수준을 보여 주었다.

하나의 잠재요인에 대한 두 개 이상의 측정도 구가 상관관계를 갖는 정도인 집중 타당성을 평 가하기 위해 표준화 요인 부하량(standardized factor loading)의 크기, 잠재요인 신뢰도(construct reliability; CR) 값의 크기, 평균분산 추출값 (average variance extracted; AVE)의 크기를 검토하였다. 〈표 3〉에서 보는 바와 같이 표준화 요인 부하량은 모두 0.7 이상으로 나타났으며 통계적으로 유의적이었다. 그리고 잠재요인 신 뢰도 값은 0.7 이상으로 나타났고, 평균분산 추 출값 또한 0.6 이상으로 나타나 본 연구에서 사 용된 측정변수들 간에는 집중타당성이 있다고 할 수 있다. 
〈표 2〉탐색적 요인분석 및 신뢰도분석

\begin{tabular}{|c|c|c|c|c|c|c|c|}
\hline & \multicolumn{6}{|c|}{ 탐색적 요인분석 } & \multirow{2}{*}{$\begin{array}{c}\text { Cronbach's } \\
\text { Alpha }\end{array}$} \\
\hline & 태도 & $\begin{array}{l}\text { 주관적 } \\
\text { 규범 }\end{array}$ & 행위의도 & $\begin{array}{c}\text { 서비스제공자 } \\
\text { 규범 }\end{array}$ & $\begin{array}{c}\text { 참여고객 } \\
\text { 규범 }\end{array}$ & $\begin{array}{c}\text { 지각된 } \\
\text { 행 위통제 }\end{array}$ & \\
\hline att4 & .880 & & & & & & \\
\hline att5 & .833 & & & & & & \\
\hline att2 & .833 & & & & & & .904 \\
\hline att1 & .774 & & & & & & \\
\hline att3 & .716 & & & & & & \\
\hline sn2 & & .876 & & & & & \\
\hline sn1 & & .860 & & & & & .914 \\
\hline sn3 & & .793 & & & & & \\
\hline intent2 & & & .842 & & & & \\
\hline intent1 & & & .840 & & & & .945 \\
\hline intent3 & & & .807 & & & & \\
\hline pn1 & & & & .856 & & & \\
\hline pn3 & & & & .822 & & & .880 \\
\hline pn2 & & & & .805 & & & \\
\hline $\mathrm{cn} 2$ & & & & & .846 & & \\
\hline $\mathrm{cn} 3$ & & & & & .829 & & .895 \\
\hline $\mathrm{cn} 1$ & & & & & .747 & & \\
\hline $\mathrm{pbc3}$ & & & & & & .834 & \\
\hline $\mathrm{pbc1}$ & & & & & & .825 & .851 \\
\hline pbc2 & & & & & & .802 & \\
\hline
\end{tabular}

\section{2 측정 동일성 검증}

자기 감시성의 조절변수 역할을 검증하기에 앞서 집단간 이론적 구조가 같은지 검증하고자 측정 동일성 검증을 실시하였다. 먼저 자기 감 시성에 따른 형태 동일성은 아무런 제약을 가 하지 않은 상태의 모형에 집단간 자료를 동시에 투입하여 분석하였다. 〈표 4〉와 같이 모형의 적 합도 지수를 확인한 결과 TLI는 0.926, RMSEA
는 0.056으로 좋은 적합도 수준을 보였으므로 형태 동일성이 검증되었다. 다음으로 측정 동일 성 검증을 위해 아무런 제약을 가하지 않은 형 태 동일성 모형과 요인계수에 동일화 제약을 가정한 측정 동일성 모형과의 $\chi^{2}$ 차이검증을 하였다. 형태 동일성 모형에 비해 측정 동일성 모형의 $\chi^{2}$ 차이값은 11.728 로 두 모형은 통계 적으로 유의한 차이가 없어서 측정 동일성이 검증되었다. 그리고 TLI와 RMSEA를 함께 고 
〈표 3〉 확인적 요인분석 및 집중 타당성

\begin{tabular}{|c|c|c|c|c|c|c|c|}
\hline & Indicator & $\begin{array}{c}\text { Factor } \\
\text { Loading }\end{array}$ & $\begin{array}{c}\text { Standardized } \\
\text { Factor Loading }\end{array}$ & $\mathrm{t}$-value & $\mathrm{SMC}$ & $\mathrm{CR}$ & AVE \\
\hline \multirow{5}{*}{ 태도 } & att1 & 1.000 & .795 & - & .632 & \multirow{5}{*}{.841} & \multirow{5}{*}{.660} \\
\hline & att2 & .962 & .816 & 19.782 & .666 & & \\
\hline & att3 & 1.097 & .762 & 18.117 & .581 & & \\
\hline & att4 & 1.115 & .874 & 21.588 & .764 & & \\
\hline & att5 & 1.054 & .812 & 19.648 & .659 & & \\
\hline \multirow{3}{*}{$\begin{array}{l}\text { 주관적 } \\
\text { 규범 }\end{array}$} & sn1 & 1.000 & .858 & - & .736 & \multirow{3}{*}{.834} & \multirow{3}{*}{.788} \\
\hline & $\operatorname{sn} 2$ & 1.114 & .947 & 28.351 & .897 & & \\
\hline & sn3 & 1.009 & .855 & 24.551 & .731 & & \\
\hline \multirow{3}{*}{$\begin{array}{c}\text { 서비스제공자 } \\
\text { 규범 }\end{array}$} & pn1 & 1.000 & .814 & - & .663 & \multirow{3}{*}{.737} & \multirow{3}{*}{.709} \\
\hline & pn2 & 1.118 & .897 & 21.945 & .805 & & \\
\hline & pn3 & .940 & .813 & 19.853 & .660 & & \\
\hline \multirow{3}{*}{$\begin{array}{c}\text { 참여고객 } \\
\text { 규범 }\end{array}$} & $\mathrm{cn} 1$ & 1.000 & .881 & - & .775 & \multirow{3}{*}{.792} & \multirow{3}{*}{.747} \\
\hline & $\mathrm{cn} 2$ & 1.020 & .920 & 27.689 & .847 & & \\
\hline & $\mathrm{cn} 3$ & .873 & .787 & 21.642 & .620 & & \\
\hline \multirow{3}{*}{$\begin{array}{c}\text { 지각된 } \\
\text { 행위통제 }\end{array}$} & $\mathrm{pbc1}$ & 1.000 & .832 & & .693 & \multirow{3}{*}{.730} & \multirow{3}{*}{.662} \\
\hline & $\mathrm{pbc} 2$ & 1.153 & .891 & 20.736 & .795 & & \\
\hline & pbc3 & .847 & .707 & 16.597 & .500 & & \\
\hline \multirow{3}{*}{ 행위의도 } & intent1 & 1.000 & .910 & & .827 & \multirow{3}{*}{.864} & \multirow{3}{*}{.856} \\
\hline & intent2 & 1.082 & .976 & 39.568 & .953 & & \\
\hline & intent3 & .977 & .888 & 31.097 & .788 & & \\
\hline
\end{tabular}

〈표 4〉 측정 동일성 검증

\begin{tabular}{c|c|c|c|c|c|c}
\hline 모델 & $\chi^{2}$ & $\mathrm{df}$ & TLI & RMSEA & $\Delta \chi^{2}$ & $\Delta$ if \\
\hline \hline 형태 동일성 & $551.297^{* * *}$ & 218 & 0.926 & 0.056 & & \\
\hline 측정 동일성 & $563.024^{* * *}$ & 230 & 0.930 & 0.055 & 11.728 & 12 \\
\hline
\end{tabular}

* $\mathrm{p}<0.1,{ }^{* *} \mathrm{p}<0.05,{ }^{* * *} \mathrm{p}<0.01$

려한 결과 TLI는 0.926에서 0.930으로, RMSEA

는 0.056 에서 0.055 로 약간 향상된 지수를 보여

주고 있어 집단간 측정 동일성 검증은 재확인 되었다.

\section{3 가설 검증}

가설 1 에서 5 까지의 검증은 기존 계획된 행위 이론에서 이야기 한 소비자의 태도, 주관적 규 
범, 지각된 행위통제와 본 연구에서 확장하여 추가한 서비스제공자 규범과 참여고객 규범을 모두 고려했을 때의 이용구매의도에 미치는 영 향 관계를 알아보았다. 검증결과는 아래의 〈표 5)과 같이 나타났다.

제안모형의 적합도는 $\chi^{2}=468.236(\mathrm{p}=0.000)$, $\mathrm{df}=155, \mathrm{GFI}=0.910, \mathrm{AGFI}=0.879, \mathrm{NFI}=0.940$, $\mathrm{NNFI}=0.949, \mathrm{CFI}=0.959, \mathrm{RMSEA}=0.065$ 로 나타나 적정수준으로 평가할 수 있었다. 또한 분석결과 태도( $0.479, t=7.516)$, 주관적 규범 (0.236, $\mathrm{t}=4.121)$, 참여고객 규범(0.117, $\mathrm{t}=$ $1.732)$, 지각된 행위통제 $(0.481, t=8.473)$ 는 행 위의도에 유의한 영향을 미치는 요인으로 나타 났다.

〈표 5〉에서 보는 바와 같이 기존의 계획된 행위이론에서 제시했던 태도, 주관적 규범, 지 각된 행위통제는 이용구매의도에 유의한 영향 을 미치는 것으로 나타났다. 하지만 본 연구에 서 새롭게 확장된 개념으로 제시한 서비스제공 자 규범은 이용구매의도에 미치는 영향력이 유 의하지 않게 나타났다. 다만 새롭게 확장된 개 념으로 제시한 참여고객 규범은 유의수준 0.1 에 서 이용구매의도에 영향을 미치는 것으로 나타
났다. 전체적으로 보았을 때 태도와 지각된 행 위통제가 이용구매의도에 상대적으로 큰 영향 력을 미치는 것으로 나타나고 있다.

가설 6 에 대한 분석으로 본 연구에서는 자기 감시성을 중위수로 기준으로 하여 낮은 그룹 (209명)과 높은 그룹(275명)으로 나누어 집단 간 차이분석을 하였다. 가설 6 에 대한 검증은 다음의 〈표 6〉과 같다. 자기 감시성이 낮은 집 단의 경우 주관적 규범 $(0.284, t=3.302)$ 요인이 행위의도에 유의한 영향을 미치는 것으로 나타 났으며, 자기 감시성이 높은 집단의 경우도 주 관적 규범 $(0.208, t=2.735)$ 요인이 행위의도에 유의한 영향을 미치는 것으로 나타났다. $\chi^{2}$ 차 이검증을 통해서 비교한 결과 주관적 규범에 대한 자기 감시성의 조절효과는 나타나지 않았 다 $\left(\Delta \chi^{2}=0.428, \mathrm{p}>0.05\right)$.

하지만 〈표 6〉을 살펴보면, 서비스제공자 규 범과 참여고객 규범의 경우, 자기 감시성이 낮 은 집단에서는 행위의도에 영향을 미치는 것으 로 나타났으며, 자기 감시성이 높은 집단에서는 영향을 미치지 않는 것으로 나타났다. 〈표 7〉에 서 보는 바와 같이 $\chi^{2}$ 차이검증을 통해서 비교 한 결과, 서비스제공자 규범과 참여고객 규범에

〈표 5〉 행위의도에 미치는 영향력 검증 결과

\begin{tabular}{c|c|c|c|c|c}
\hline 가설 & 경로 & 경로계수 & 표준오차 & t-value & 채택여부 \\
\hline \hline $\mathrm{H} 1$ & 태도 $\rightarrow$ 행위의도 & .479 & .064 & $7.516^{* * * *}$ & 채택 \\
\hline $\mathrm{H} 2$ & 주관적 규범 $\rightarrow$ 행위의도 & .236 & .057 & $4.121^{* * *}$ & 채택 \\
\hline $\mathrm{H} 3$ & 서비스제공자 규범 $\rightarrow$ 행위의도 & -.056 & .063 & -.888 & 기각 \\
\hline $\mathrm{H} 4$ & 참여고객 규범 $\rightarrow$ 행위의도 & .117 & .068 & $1.732^{*}$ & 채택 \\
\hline $\mathrm{H} 5$ & 지각된 행위통제 $\rightarrow$ 행위의도 & .481 & .057 & $8.473^{* * *}$ & 채택 \\
\hline
\end{tabular}

* $\mathrm{p}<0.1, * * \mathrm{p}<0.05$, *** $\mathrm{p}<0.01$

$\chi^{2}=468.236(\mathrm{p}=0.000), \mathrm{df}=155, \mathrm{GFI}=0.910, \mathrm{AGFI}=0.879, \mathrm{NFI}=0.940, \mathrm{NNFI}=0.949, \mathrm{CFI}=0.959, \mathrm{RMSEA}=0.065$ 
대한 자기 감시성의 조절효과는 각각 0.01 과 0.05 수준에서 유의한 것으로 나타나고 있다 $(\Delta$ $\left.\chi^{2}=8.941, \mathrm{p}<0.01, \Delta \chi^{2}=4.448, \mathrm{p}<0.05\right)$.

가설 6 에서 자기 감시성의 개념을 주위사람들 을 의식하는 정도로만 단순히 생각하여 자기 감시성이 높은 경우에는 주관적 규범, 서비스제 공자 규범, 참여고객 규범이 행위의도에 더 큰 영향력을 미칠 것으로 예상하였다. 하지만 〈표 6)에서 보는 바와 같이 흥미롭게도 예상과는 달리 서비스제공자 규범과 참여고객 규범이 행 위의도에 미치는 영향력이 자기 감시성이 높은 경우보다 낮은 경우에 상대적으로 더 크게 나 타났다.

\section{VI. 결론}

\section{1 연구의 요약 및 시사점}

본 연구는 기존 계획된 행위모델에서 행위의 도에 영향을 미치는 주요변수로 제시한 태도와 주관적 규범 그리고 통제된 신념 이외에 고려 되어야 할 또 다른 규범개념인 서비스제공자 규범과 참여고객 규범을 제시하였다. 아울러 자 기 감시성의 정도에 따라 주요변수가 행위의도 에 미치는 영향력이 달라진다는 조절적 역할에 대해서도 고찰하였다.

연구 결과, 서비스를 이용할 때에도 기존의

〈표 6〉 자기 감시성에 따른 집단간 경로계수 비교

\begin{tabular}{c|c|c|c|c}
\hline \multirow{2}{*}{ 경로 } & \multicolumn{2}{|c|}{ 낮은 집단 $(\mathrm{N}=209)$} & \multicolumn{2}{c}{ 높은 집단 $(\mathrm{N}=275)$} \\
\cline { 2 - 5 } & Estimate & $\mathrm{t}$-value & Estimate & $\mathrm{t}$-value \\
\hline \hline 태도 $\rightarrow$ 행위의도 & .525 & $4.698^{* * *}$ & .474 & $5.481^{* * *}$ \\
\hline 주관적 규범 $\rightarrow$ 행 위의도 & .284 & $3.302^{* * *}$ & .208 & $2.735^{* *}$ \\
\hline 서비스제공자 규범 $\rightarrow$ 행 위의도 & -.318 & $-2.975^{* *}$ & .085 & 1.026 \\
\hline 참여고객 규범 $\rightarrow$ 행 위의도 & .352 & $2.652^{* *}$ & .030 & .391 \\
\hline 지각된 행위통제 $\rightarrow$ 행위의도 & .413 & $3.440^{* * *}$ & .504 & $7.641^{* * *}$ \\
\hline
\end{tabular}

* $\mathrm{p}<0.1,{ }^{* *} \mathrm{p}<0.05,{ }^{* * *} \mathrm{p}<0.01$

〈표 7〉 자기 감시성에 따른 집단간 경로계수 차이 비교

\begin{tabular}{c|c|c|c|c}
\hline 경로 & $\mathrm{x}^{2}$ & $\mathrm{df}$ & $\mathrm{x}^{2}$ 차이 & sig \\
\hline \hline Free & 701.988 & 310 & - & - \\
\hline 태도 $\rightarrow$ 행 위의도 & 702.117 & 311 & .128 & $\mathrm{n} . \mathrm{s}$ \\
\hline 주관적 규범 $\rightarrow$ 행 위의도 & 702.416 & 311 & .428 & $\mathrm{n} . \mathrm{s}$ \\
\hline 서비스제공자 규범 $\rightarrow$ 행위의도 & 710.929 & 311 & 8.941 & $\mathrm{p}<0.01$ \\
\hline 참여고객 규범 $\rightarrow$ 행위의도 & 706.437 & 311 & 4.448 & $\mathrm{p}<0.05$ \\
\hline 지각된 행위통제 $\rightarrow$ 행위의도 & 702.411 & 311 & .423 & $\mathrm{n} . \mathrm{s}$ \\
\hline
\end{tabular}


계획된 행위이론이 제시하는 변수 간 인과관계 는 재검증되었다. 또한 서비스 구매의도에 영향 을 미치는 요인으로 기존의 소비자 태도뿐만 아니라 그 서비스 내에 참여하는 고객의 규범 또한 유의한 영향을 미치는 것으로 나타났다. 하지만 서비스제공자의 규범은 유의미한 결과 를 나타내지 못했다. 이는 소비자가 상대적으로 서비스제공자보다는 다른 참여고객의 존재를 의식하는 경향이 더 높다는 것으로 생각할 수 있다. 서비스제공자는 자신에게 서비스를 해야 만 하는 존재로 생각하여 상대적으로 의식하는 정도가 낮았던 것 같다.

또한 자기 감시성의 조절적 역할에 대해 분석 해 본 결과, 자기 감시성의 조절적 역할에 대한 추론은 할 수 있지만 그 방향성에 있어서 생각 했던 것과는 달리 흥미로운 결과를 나타냈다. 일상적으로 자기 감시성이 높은 상황에서 서비 스고객 규범이나 참여고객 규범이 행위의도에 상대적으로 더 높은 영향력을 가질 것으로 생 각했지만 분석결과에서는 오히려 상대적으로 더 낮은 영향력을 가지는 것으로 나타난 것이다. 자기 감시성에 따라 상대적 영향력이 달라지기 는 하지만 예상했던 것과는 달리 나타나는 이 유에 대해서는 조금 더 살펴봐야 할 것이다. 하 지만 자기 감시성의 측정항목을 살펴보면 감시 성이 높은 경우 남을 의식하는 정도가 높은 것 으로만 의미를 국한할 것이 아니라 더 나아가 서 오히려 남과의 어울림을 즐기고 자신이 다 른 사람들과 어우러지는 상황에 맞추기 위해 자신을 변화시키고자 하는 관심이 높은 것으로 해석해야 할 필요가 있는 것으로 보인다. 실제 로 Aron O'Cass(2000)는 자기 감시성이 높은 사람의 경우 Public self를 강조하고 어떻게 자
신을 상황에 맞도록 적절하게 변화시킬까 그리 고 어떻게 그 상황에서 행동할지에 관심이 있 는 소비자라고 말하고 있다. 만일 그렇다면 자 기 감시성이 높은 사람은 이미 자신은 특정 상 황에 자신을 변화시킬 수 있는 자신감 또는 능 력이 있다고 전제하는 것일 수 있다. 따라서 자 기 감시성이 높은 경우 남을 의식하는 경향이 더 뚜렷하더라도 그 상황에 자신을 변화시킬 수 있다고 믿기 때문에 오히려 서비스제공자 규범이나 참여고객 규범의 영향력이 상대적으 로 덜 나타나는 것이 아닌가 추측된다.

본 연구결과에서 한 가지 특이한 점은 자기 감시성이 낮은 집단에서 서비스제공자 규범의 영향력이 가설과는 다른 방향으로 유의한 것으 로 나타나고 있다. 이 점은 통합표본에서 가설 4 가 기각되는 결과와 직결되는 문제이기도 하 다. 이러한 결과가 나타난 이유는 매우 다양할 수 있다. 측정변수의 문제일 수도 있고, 성격이 매우 다른 두 업종이 뒤섞인 표본을 대상으로 분석한 결과일 수도 있다. 하지만 가장 설득력 있는 이유 중 하나는 서비스제공자 규범의 측 정항목 자체가 사실 고객들에게 상당한 부담으 로 작용했을 가능성이 있다. 자기 감시성이 낮 은 사람들은 다른 사람들과 관계하는 특정상황 에 자신을 변화시키기가 어렵거나 그러한 것에 자신이 없는 사람들이라고 할 수 있다. 이러한 고객들은 특히 '서비스제공자는 내가 특정 서비 스를 이용할 때 적극적으로 도움을 줄 것이다' 라는 항목이나 '서비스제공자는 내가 특정 서비 스를 이용해야 한다고 생각한다'와 같은 항목에 서 최소한이라도 꼭 대면해야 하는 서비스제공 자에 대해 적극적 관계를 해야만 하는 상황으 로 지각했을 가능성이 있다. 그렇다면 서비스제 
공자의 존재를 의식하는 경향이 매우 높아 오 히려 이러한 생각들이 더 큰 부담으로 작용하 여 오히려 행위의도를 낮추는 결과를 가져왔을 수도 있을 것이다. 반면에 참여고객에 대해서는 상대적으로 대면을 피하거나 덜 부담스럽게 생 각하여 같은 항목에 대해 그리 민감하게 반응 하지 않았고 따라서 다른 참여고객의 존재를 의식하는 경향이 높을 경우에는 행위의도에 순 기능적 영향을 미치는 것으로 볼 수 있다.

본 연구를 통해서 서비스판매 관리자에게 다 음과 같은 시사점을 제공할 수 있다. 서비스 판 매 관리자는 주요 고객층의 관리에 만전을 기 할 필요가 있다. 왜냐하면 소비자들이 타 고객 층의 반응을 의식하고 있기 때문이다. 이러한 고객층의 관리는 두 가지 관점에서 논의할 필 요가 있다. 판매관리자는 표적 고객을 특정 소 비자층으로 국한시키거나 아니면 다양한 소비 자층이 이용하고 있는 것으로 인식시킬 필요가 있는 것이다. 표적고객을 특정 소비자층으로 국 한시킨다면 그 소비자층의 서비스 구매를 유도 하는데 도움이 될 수 있을 것이다. 반면 고객을 다양한 소비자층으로 구성한다면 특정 소비자 층이 방문하기를 꺼리게 될 가능성을 낮출 수 있기 때문이다. 이 경우 연령대에 따른 시장세 분화보다는 고객의 혜택에 따른 시장구분과 표 적소비자의 선정이 더 바람직하다고 하겠다.

아울러 다음과 같은 몇 가지 학문적 가치와 기대를 생각해 볼 수 있다. 첫째, 기존의 행위 이론에서 중요한 요소로 지목되었던 태도나 주 관적 규범 이외에 서비스이용이나 구매상황에 서 고객의 행위의도에 영향을 미칠 수 있는 또 하나의 중요한 개념을 제시하는 의의가 있다. 둘째, 고객이 실제로 어떤 행동을 하기까지는
준거인의 영향력뿐만 아니라 서비스시스템 내 에 있는 서비스제공자나 참여고객에 대한 지각 모두가 고객의 행동에 영향력을 발휘할 수 있 다는 서비스마케팅에서의 이론을 행위모델로 실증하는 의미가 있다. 셋째, 변수들 간의 상대 적 영향력을 살펴보고, 이에 대한 조절요인을 살펴봄으로서 기존의 연구에서 미흡했던 점들 을 보완하여 고객행위를 좀 더 자세히 이해하 고 그 방향을 예측하는데 도움이 될 것으로 기 대한다. 마지막으로 기존 행위의도모형과 그 확 장모형이 발표될 때마다 폭발적으로 증가해왔 던 실증연구가 본 연구에서 제시한 이론으로 말미암아 다시 활발한 실증연구가 이루어지기 를 기대한다.

\section{2 연구의 한계점}

본 연구는 고객의 제품구매행위에 중요한 요 소로 지목되었던 태도나 주관적 규범 이외에 서비스구매상황에서 고객의 행동의도에 영향을 미칠 수 있는 또 하나의 중요한 규범 개념을 소개하였고 그 중요성을 일깨웠다는데 시사점 이 있다. 고객이 실제로 어떤 행동을 하기까지 는 준거인의 영향력뿐만 아니라 서비스시스템 내에 있는 참여고객에 대한 지각 모두가 고객 의 행동에 영향력을 발휘할 수 있다는 점을 실 증적으로 분석했다는데 그 의의가 있다고 하겠 다. 그러나 본 연구는 다음과 같은 한계점을 가 지고 있고 이러한 한계점들은 또한 다양한 후 속 연구방향을 제시하고 있다.

첫째, 본 연구는 다소 한정된 서비스를 대상 으로 자료를 수집하여 분석하였기 때문에 그 연구결과를 일반화하기에 다소 무리가 있다. 따 
라서 본 연구의 결과는 다양한 서비스 상황에 서 다양한 표본계층을 이용하여 재검증될 필요 가 있다.

둘째, 다양한 서비스업태 중 연령층에 따라 다소 민감하게 반응할 수 있는 홍대클럽이용과 세신서비스이용만을 선정하였다. 하지만 사전조 사가 다소 미흡하였다고 본다. 따라서 향후 보 다 명확한 사전조사를 통해 서비스업종을 선정 하는데 있어서 타당성을 높여야 할 것으로 판 단된다. 특히 사전조사 시점에 민감성관련 변수 를 측정하고 비교분석하여 업종별 분석결과를 제시한 후 선정된 이유를 기술할 필요가 있다 고 하겠다.

셋째, 본 연구에서 서비스제공자 규범과 참여 고객 규범의 영향력을 검증하기 위해 과거 주 관적 규범의 측정항목들을 차용하였다. 하지만 좀 더 서비스제공자 규범과 참여고객규범 개념 을 잘 정립하기 위해서는 서비스 관련 규범들 의 측정항목을 좀 더 면밀하게 개발해야 할 필 요가 있다고 하겠다.

넷째, 본 연구에서는 서비스 구매행위의도에 만 초점을 맞추었지만 의도가 실제 행동으로 꼭 이루어지는 것은 아니므로 향후 연구에서는 서 비스상황에 있어서의 의도와 실제 행동 간의 관 계까지도 고려해야할 필요성이 있다고 하겠다.

마지막으로 본 연구는 새로운 서비스 참여고 객 규범과 아울러 서비스제공자 규범을 소개하 였지만, 그 과정에서의 논리적인 근거가 다소 미약하였다. 또한 서비스제공자 규범에 관한 영 향력은 미미한 것으로 나타났다. 아울러 다른 조절변수들에 대한 보다 심층적인 고찰이 필요 한 것으로 보인다. 앞으로 주요 변수들에 대한 보다 명확한 구분 및 개념정리와 다양한 자료
를 통한 검증을 통하여 계획된 행위모형을 보 다 정교화 할 수 있을 것으로 기대한다.

〈논문 접수일: 2009. 04. 20〉 〈게재 확정일: 2009. 07. 10〉

\section{참고문헌}

김명소, 한영석(2001), “합리적 행위이론과 계획 된 행동이론에 의한 온라인 구매행동 이 해,” 한국심리학 회지: 사회 및 성격, 15 (3), 17-32.

유창조(2004), "소비자 구매행동에 대한 브랜드 의 태도에 관한 의견과 향후 연구방향," 소 비자학연구, 15(2), 109-113.

이상현, 유창조, 장문성(2007), “서비스 상황에서 구매 행위의도에 영향을 미치는 확장된 모형 에 대한 실증분석," 광고연구, 74(1), 89-110. 이학식, 김영(1998), "태도-행동 관계에 대한 조 정변수들의 역할: 대선 투표행동의 체계에 서," 소비자학연구, 9(2), 37-64.

이학식, 최재익, 임지훈(2004), “소비자 구매행 동에 대한 브랜드의 태도: 소비자-브랜드 관 계에서의 역할," 소비자학연구, 15(2), 85104.

조대우, 황경연(2001), "인터넷뱅킹이용에 영향 을 미치는 요인" - 계획된 행동이론을 중심 으로 -, 경영학연구, 30(4), 1225-1249.

Ajzen, I. (1985), "From Intentions to Actions:

A Theory of Planned Behavior," In I. Kuhl \& J. Beckmann(Eds.), Action Control from Cognition to Behavior, NewYork: 
Springer, 11-39.

Ajzen, I. (1988), “Attitudes, Personality, and Behavior," Chicago: Dorsey Press.

Ajzen, I. (1991), "The Theory of Planned Behavior", Organizational Behavior and Human Decision Processes, 50, 179-211.

Ajzen, I. (2002), "Constructing a TpB Quesionnaire: Conceptual and Methodological Considerations," Working Paper, University of Massachusetts, Amherst, (available online at http://www-unix.oit.umass.edu/ aizen/ pdf/tpb.measurement.pdf).

Ajzen, I. and M. Fishbein (1980), Understanding Attitudes and Predicting Social $\mathrm{Be}^{-}$ havior, Englewood Cliffs, NJ: PrenticeHall.

Anderson, J. C. and D. W. Gerbing (1988), "Structural Eqauations Modeling in Practice: A Review and Recommended Two Step Approach," Psychological Bulletin, 103 (May), 411-423.

Bagozzi, R. P. (1981), “Attitudes, Intentions, and Behavior: A Test of Some Key Hypotheses," Journal of Personality and Social Psychology, 41, 607-627.

Bearden, W. O. and A. G. Woodside (1978), "Situational and Extended Attitude Models as Predictors of Marijuana Intentions and Reported Behavior," Journal of Social Psychology, 106, 57-67.

Bentler, P. M. and G. Speckart (1979), "Models of Attitude-Behavior Relations," Psychological Review, 86, 452-464.
Berger, I. E., and A. A. Mitchell (1989), "The Effect of Advertising on Attitude Accessibility, Attitude Confidence, and the Attitude-Behavior Relationship," Journal of Consumer Research, 16, 269-279.

Bettencourt, L.A. (1997), "Customer Voluntary Performance: Customers as Partners in Service Delivery," Journal of Retailing, 73 (Fall), 383-406.

Budd, R. J. (1986), “Predicting Cigarette Use: The Need to Incorporate Measures of Salience in the Theory of Reasoned Action," Journal of Applied Social Psychology, 16, 663-685.

Budd, R. and C. P. Spencer (1984), "Latitude of Rejection, Centrality and Certainty: Variables Affecting the Relationship between Attitudes, Norms, and Behavioural Intentions," British Journal of Social Psychology, 23, 1-8.

Burnkrant, R. and T. J. Page (1982), "The Structure and Antecedents of the Normative and Attitudinal Components of Fishbein's Theory of Reasoned Action," Journal of Experimental Social Psychology, 24, 66-87.

Chau, P.Y.K. (1996), “An Empirical Investigation on Factors Affecting the Acceptance of CASE by Systems Developers," Information and Management, 30, 269-280.

Chebat, J. C. and P. Kollias (2000), "The Impact of Empowerment on Customer Contact Employees' Roles in Service Organizations," Journal of Service Research, 3 
(August), 66-81.

Cooke, R. and P. Sheeran (2004), "Moderation of Cognition-Intention and CognitionBehaviour Relations: A Meta-Analysis of Properties of Variables From The Theory of Planned Behaviour," British Journal of Social Psychology, 43, 159-186.

Czepiel, J. A. (1990), "Service Encounters and Service Relationships: Implications for Research," Journal of Business Research, 20 (1), 13-21.

Farley, J. U., D. R. Lehman, and M. J. Ryan (1981), "Generalizing From Imperfect Replication," Journal of Business, 54, 597-610.

Fazio, R. H. and C. J. Williams (1986), "Attitude Accessibility as a Moderator of the Attitude Perception and Attitude-Behavior Relations: An Investigation of the 1984 Presidential Election," Journal of Personality and Social Psychology, 51, 505-514.

Fazio, R. H., M. C. Powell, and C. J. Williams (1989), "The Role of Attitude Accessibility in the Attitude-to-Behaviour Process," Journal of Consumer Research, 16, 280-288.

Fishbein, M. (1967), "Readings in Attitude Theory and Measurement," New York: Wiley.

Fishbein, M. and I. Ajzen (1975), "Belief, Attitude, Intention, and Behavior: An Introduction to Theory and Research," Reading, MA: Addison-Wesley.

Gefen, D., Straub, D.W., and Boudreau, M.C. (2000), "Structural Equation Modeling and
Regression: Guidelines for Research Practice," Communications of the Association for Information Systems, 4(7), 1-70.

Gould, S. (1993), “Assessing self-concept discrepancy in consumer behavior: The joint effect of private self-consciousness and selfmonitoring," Advances in Consumer Research, 20, 419-424.

Grove, S.J. and R. P. Fisk (1997), "The Impact of Other Customers on Service Experiences: A Critical Incident Examination of 'Getting Along,", Journal of Retailing, 73 (Spring), 63-85.

Gittell, J. H. (2002), "Relationships Between Service Providers and Their Impact on Customers," Journal of Service Research, 4 (May), 299-311.

Igbaria, M., N. Zinatelli, and P. Cragg (1997), "Personal Computing Acceptance Factors in Small Firms: A Structural Equation Model," MIS Quarterly, 21 (September), 279-305.

Jöreskog, K. G. (2000), "Latent Variable Scores and Their Uses," Lincolnwood, IL: Scientific Software International, Inc.

Jöreskog, K. G. and D. Sörbom (1993), "LISREL 8: The SIMPLIS Command Language," Chicago, IL: Scientific Software International, Inc.

Jöreskog, K. G. and D. Sörbom (1999), "PRELIS 2: User's Reference Guide," Chicago, IL: Scientific Software International, Inc.

Lutz, R. J. (1991), "The Role of Attitude Theory in Marketing," in Perspectives in 
Consumer Behavior, 4th ed. Kassarijian \& Robertson, 317-339. Prentice Hall: NJ. Madden, T. J., P. S. Ellen, and I. Ajzen (1992), "A Comparison of the Theory of Planned Behavior and the Theory of Reasoned Action," Personality \& Social Psychology Bulletin, 18 3-9.

Miniard, P. and J. B. Cohen (1983), "Modeling Personal and Normative Influences on $\mathrm{Be}^{-}$ havior," Journal of Consumer Research, 10, 169-179.

O'Cass, Aron (2000), "A psychometric Evaluation of a revised version of the Lennox and Wolfe revised self-monitoring scale," Psychology \& Marketing, 17(5), 397-419.

Parasuraman, A., V. A. Zeithaml, and L. L. Berry (1985), “A Conceptual Model of Service Quailty and It's Implications for Future Research," Journal of Marketing, 49 (Fall), 41-50.

Pavlou, P. A. and M. Fygenson (2006), "Understanding and Predicting Electronic Commerce Adoption: An Extension of the Theory of Planned Behavior," MIS Quarterly, 30(1), 115-143.

Petty, R. E. and J. T. Cacioppo (1986), "The Elaboration Likelihood Model of Persuasion," in L. Berkowitz, Advances in Experimental Social Psychology, 19, 123-205, San Diego, CA: Academic Press.

Petty, R. E., J. T. Cacioppo, and D. Schuman (1983), "Central and Peripheral Routes to Advertising Effectiveness: The Moderating
Role of Involvement," Journal of Consumer Research, 10, 135-146.

Pieters, R. G. M, and B. Verplanken (1995), "Intention-Behaviour Consistency: Effects of Consideration Set Size, Involvement, and Need for Cognition," European Journal of Social Psychology, 25, 531-543.

Schlegel, R. P., J. R. d’ Avernas, M. P. Zanna, N. H. DeCourville, S. R. Manske (1992), "Problem Drinking: A Problem for the Theory of Reasoned Action?" Journal of Applied Social Psychology, 22, 358-385.

Schumacker, R. E. (2002), "Latent Variable Interaction Modeling," Structural Equation Modeling, 9(1), 40-54.

Sheeran, P. (2002), "Intention-Behaviour Relations: A Conceptual and Empirical Review," European Review of Social Psychology, 12, 1-36.

Sheeran, P. and C. Abraham (2003), "Mediator of Moderators: Temporal Stability of Intention and the Intention-Behaviour Relation," Personality and Social Psychology Bulletin, 29, 205-215.

Sheppard, B. H., J. Hartwick, and P. Warshaw (1988), "The Theory of Reasoned Action: A Meta-Analysis of Past Research with Recommendations for Modifications and Future Research," Journal of Consumer Research, 15(3), 325-343.

Shimp, T. A. and A. Kavas (1984), "The Theory of Reasoned Action Applied to Coupon Usage”, Journal of Consumer Research, 11, 
795-808.

Skinner, W. F. and A. M. Cattarello (1989), "Understanding the Relationships Among Attitudes, Group Norms, and Behavior Using Behavioral Commitment: A Structural Equation Analysis of Marijuana Use," Journal of Applied Social Psychology, 19, 1268-1291.

Slama, M., \& Celuch, K. (1995), "Self Presentation and Consumer Interaction Styles," Journal of Business and Psychology, 10, 19-30.

Snyder, M. (1974), "Self-monitoring of expressive behavior," Advances in Experimental Social Psychology, 12, 86-128.

Snyder, M. (1979), "Self-monitoring process," Advances in Experimental Social $\mathrm{PSy}^{-}$ chology, 12, 86-128.

Snyder, M., \& Gangestad, S. (1986), "On the nature of Self-monitoring: Matters of Assessment, Matters of Validity," Journal of Personality and Social Psychology, 51, 125-139.
Snyder, M., \& Kendzierski, D. (1982), "Choosing social situations: A Strategy for generating correspondence between attitudes and behavior," Journal of Personality, 50, 280295.

Taylor, S. and P. A. Todd (1995), “Decomposition and Crossover Effects in the Theory of Planned behavior: A Study of Consumer Adoption Intentions," International Journal of Research in Marketing, 12, 137155.

Warshaw, P. R. (1980), “A New Model for Predicting Behavioral Intentions: An Alternative to Fishbein," Journal of Marketing Research, 153-172.

Zeithaml, V.A, M. J. Bitner, and D. D. Gremler (2006), “Service Marketing: Integrating Customer Focus Across the Firm," 4th ed. McGraw-Hill. 